\title{
NICOLÁS MAQUIAVELO: UN HOMBRE DE ACCIÓN, UN FIEL SERVIDOR
}

María Teresa Navarro Salazar

U.N.E.D.

Pocos nombres a lo largo de la historia habrán resultado tan negativamente connotados como el del Secretario florentino Nicolás Maquiavelo', y hasta tal punto se le ha considerado peligroso y nefasto que no sólo su apeIlido ha pasado a denotar un comportamiento artero y falaz, sino que el hipocorístico de su nombre de pila ha llegado incluso a designar al diablo en el mundo anglosajón ${ }^{2}$.

Los historiadores de la politica han ensalzado su figura como creador de la ciencia moderna de la política, los moralistas, los teólogos y otros muchos estudiosos procedentes de distintos campos científicos han condenado tajantemente sus escritos en agrias polémicas que han generado una fecunda estirpe de maquiavelistas y antimaquiavelistas ${ }^{3}$. Los filólogos, además de concederle el mérito de haber conferido al análisis de la lengua una dimensión politica ${ }^{4}$, han reconocido el placer que les produce adentrarse en cualquiera de sus obras, para analizar un estilo de lenguaje seco y expeditivo unas veces, depurado y sublime en otras ocasiones, pero siempre personal e inimitable $e^{5}$, bien sea cuando trata de asuntos de Estado, o ilustra con humor algunos usos y costumbres propios de otros países, escribe cartas familiares,

1 El joven Nicolás Maquiavelo resultó elegido Secretario de la Segunda Cancilleria o Cancilleria de los Diez el 28 de mayo de 1498 en concurrencia entre otros con un notario, Andrea di Romolo y un profesor universitario Francesco Gaddi. Ocupó el cargo hasta 1512.

${ }^{2}$ Cfr. maquiavélico y maquiavelismo, en D.R.A.E. Old Nick es uno de los muchos eufemismos empleados para designar a Lucifer en paises de habla inglesa.

3 Sobre el antimaquiavelismo en España, véase: Helena Piugdoménech. «Maquiavelo, la monarquia y la Inquisición española", en Boletin de la Real Academia de Buenas Letras, XXXVI, 11975-76, pp. 203-210.

4 Ignazio Baldelli, «ll dialogo sulla lingua", en Cultura e scuola, nos. 33-34, enero-junio 1970, pp. 255-259.

A pesar de que muchos estudiosos han querido ver una diferencia entre el estilo del Maquiavelo de los primeros Escritos politicos y el de las grandes obras F. Chiappelli, Nuovi studi sul linguaggio del Machiavelli, Firenze, Le Monnier, 1969 ha demostrado que en lo que concierne al lenguaje y al estilo no hay diferencias entre un Maquiavelo Secretario y un Maquiavelo autor. 
se recrea en comedias disolutas o graba para la posteridad los hechos más sobresalientes de la historia de Florencia'.

No voy a seguir una dirección ya recorrida por competentes tratadistas y documentados eruditos que han estudiado con rigor la doctrina políticomoral de Maquiavelo y sus repercusiones posteriores. Voy a intentar, simplemente, presentar al Secretario desde una perspectiva más humana, proyectando la luz sobre el hombre, con sus preocupaciones familiares, pecuniarias y laborales, tratando de iluminar alguna de las facetas menos conocidas de su vida, dirigiendo los focos hacia esa penumbra en la que transcurren los primeros años de actividad, los años de acción al servicio de la República, de la que será fiel servidor, a costa de la pérdida de todo ${ }^{7}$.

Si bien estos años de vida azarosa que se extienden hasta 1512 no fueron muchos, teniendo en cuenta que su vida activa se inicia en 1498 , si es cierto que fueron vividos intensamente y que, en su agitado acontecer, le procuraron muchos acontecimientos acerca de la vida y la naturaleza humana. Fueron la semilla de las obras teóricas escritas más tarde, durante el largo periodo de inactividad. A diferencia de otros literatos contemporáneos, Maquiavelo prefirió los hechos a las palabras, es decir, la vida a la literatura y no empezó a escribir hasta que la experiencia hubo madurado las vivencias de su juventud.

La tradición, que casi se ha convertido en ciencia, nos ha legado la imagen de un hombre rodeado por un halo de maldad, sentado ante su mesa de la cancillería, maquinando perversas insidias, con ese rostro anguloso, de pómulos prominentes, labios finos y ojos pequeños, pero vivaces, que tan bien captó en su retrato Santi di Tito. Es una imagen que se conforma tan perfectamente a la secular idea de político frío, sagaz y casi cruel que resulta dificil apartarla de la mente para dar cabida a la de ser humano, a la de hombre renacentista, preocupado por las vicisitudes de su patria, adornado de los mismos defectos y cualidades que el resto de los personajes de su época. Porque el Secretario fue una persona sensible que, en medio de los quebraderos de cabeza que la guerra le proporciona, se acuerda de proteger a los más débiles, de atender a las peticiones que le formulan los más afectados por ella $^{8}$. Y fue también un hombre familiar que, a pesar de las obligadas ausencias se preocupó por la recta formación de sus hijos, por Bernardo, al que acabará colocando en el Departamento de los Curadores de las murallas de Florencia, por Ludovico, violento y rebelde, que ya se las había visto con la

${ }^{6}$ Una versión española moderna y fiable es la de Félix Fernández Murga, Historia de Florencia, Madrid, Alfaguara, 1979.

1512 fue un año crucial en la vida de Maquiavelo, dividida en dos etapas por la lapidaria frase: post res perditas, que anotó como recordatorio de su caída en desgracia en el escrito $L a$ cagione dell'ordinanza, dove la si truovi, et quel che bisogna fare. Post res perditas.

8 Es el caso de un barquero al que los soldados han dejado sin trabajo porque le han quitado la barca ula quale mandava innanzi et indietro caricha di malvagie». (Carta del 15 de lebrero 1499 dirigida a Antonio de Ridolfis). Las cartas dirigidas a los comisarios en campaña 
policia, por Piero, por Totto y por Baccina. Pero muy especialmente por Guido, el hijo estudioso e inteligente, el que mejor comprende a su padre y al que éste escribe en los siguientes términos: "Se Iddio ti presta vita, e a me, io credo farti un uomo da bene, quando tu voglia fare parte del debito tuo" y añade "Bacia la Baccina, Piero e Totto se vi è, il quale arei avuto caro intendere se gli è guarito degli occhi. Vivete lieti e spendete meno che voi potete [...] Christo vi guardi tutti»" ${ }^{9}$. Para ayudar a su hermano Totto se sirve en más de una ocasión de los amigos. Así escribe a Vettori pidiéndole ayuda porque su único hermano, clérigo, quiere llegar a ser familiar del Papa ${ }^{10}$.

No obstante la imagen transmitida, Maquiavelo no transcurrió sus años de Secretario sentado ante una mesa redactando oficios y despachos, dando instrucciones a los comisarios de la Señoría sobre cómo conducir las campañas de Pisa o Pistoia. Fue en esos años un verdadero hombre de acción y recorrió tantas leguas a caballo que bien se puede decir de él lo que de sí mismo decía Ariosto: «e di poeta cavallar mi feo»:

En 1499, junto a Lucas Degli Albizzi y Juan Bautista Ridolfi, lo encontramos ya recorriendo a caballo la primera línea de batalla que atiende al cerco de Pisa. Es el año en el que se le encomiendan sus dos primeras legaciones: las visitas a Jacobo de Appiano, señor de Piombino y a Caterina Sforza, señora de Forli. Durante 1500 vuelve al campo de Pisa y realiza su primera misión en Francia donde sigue a la corte hasta Blois y Nantes. En 1501 desarrolla su actividad en Pistoia donde, en plena rebelión de la ciudad, se hace cargo de la situación y propone a la Señoría las medidas que hay que tomar, luego se desplaza a Cascina y Siena. Entre agosto y septiembre de 1502 viaja tres veces a Arezzo, que ya está en posesión de la República. En octubre sale de Florencia con la misión de entrevistarse con el duque Valentino y la orden expresa de "cavalcare prestissimo", y se dirige al galope hasta Imola. Se entrevista con el duque y le sigue posteriormente a Cesena, Fano y Sinigalia donde es testigo de su venganza".

Entre 1503 y 1505 lleva a cabo distintas misiones: se entrevista en Siena con Pandolfo Petrucci, viaja a Roma para informar sobre el cónclave; de regreso a Florencia es enviado de nuevo a Francia y luego a Piombino, a Castiglione del Lago, para hablar con Baglioni, a Mantua, a Siena y otra vez al campo de batalla de Pisa.

Las disposiciones para instituir las Ordenanzas de la milicia de Infanteria de Florencia datan de 1506, y de 1512 las correspondientes a la Caballería. La redacción de estas Ordenanzas no representaba más que una de las caras

proporcionan numerosos ejemplos de su humanidad y justicia. Véanse las del 11-XI; 18 XII, 1498. 27-I: 28-II; 1-XII, 1499 et passim, incluidas en: Machiavelli, Legazioni e Commissarie. Scritti di governo, a cura di Fredi Chiappelli, Beri, Laterza, 1971, vol. I.

4 Carta del 2 de abril de 1527.

10 Carta a Francesco Vettori del 13 de marzo de 1513

II De los contactos que tuvo con el duque Valentino, César Borja, surgió el informe "Descrizione del modo tenuto dal Duca Valentino nello ammazzare Vitellozzo Vitelli, Oliverotto da Fermo, il signor Pagolo e il duca di Gravina Orsinim. (1503). 
de la moneda, ya que simultáneamente el Secretario habia recorrido las zonas de Mugello y Casentino para reclutar a sus soldados. El 2 de enero de 1506 escribía a los magistrados de los Diez y se despedía: «Raccomandomi alle Signorie Vostre e a queste tramontane, che m'insegnano andare appiè' ${ }^{12}$. Durante este año se entrevista también con el Papa Julio II con el que se traslada a Cesena, Forlì e Imola. Vuelve a Florencia.

Sigue el reclutamiento de soldados en 1507 en la zona de San Giminiano y, antes de su viaje a Ginebra y Constanza, va a Siena. A principios de 1508 está ya en Bolzano, lugar en el que se encuentra la corte del emperador. De vuelta en Florencia tiene que dirigirse a San Miniato, Pescia y Pontedera con el fin de realizar nuevos reclutamientos.

Un año de especial actividad es el de 1509: recorre los distintos sectores del ejército que se prepara para presentar la definitiva batalla ante Pisa, lo vemos en Mulina di Cuosa y Fiumemorto. Va luego a Lucca, a Piombino y a Pistoia. Cuando el 8 de junio termina la guerra contra Pisa, Maquiavelo entra en la ciudad cabalgando en medio de sus batallones. Se traslada después a Mantua y Verona.

Nuevos reclutamientos y una tercera misión en Francia se desarrollan en 1510 , y en 1511 recorre en compañía de Julián de San Gallo, Pisa, Arezzo y Poggio Imperiale, con objeto de revisar las fortificaciones alli existentes. En palabras de Ridolfi: "Di segretario è ormai divenuto il tecnico militare della repubblica! $!^{13}$ Realiza una misión ante Luciano Grimaldi, señor de Mónaco y recluta en los alrededores de Florencia a 100 hombres de a caballo para incorporarlos a la nueva milicia de caballería. Efectúa su cuarta legación en Francia y casi sin poner pie a tierra sale en dirección a Pisa.

Sigue reclutando hombres por tierras de Romaña, se traslada a Pisa, Siena, de nuevo a Pisa y se enfrenta al ejército español que avanza hacia Florencia. En este año de amarguras, 1512, ve con profunda desilusión que sus milicias no son capaces de impedir el saqueo de Prato.

Con la caída del Gonfalonero Pedro Soderini, Maquiavelo queda confinado en la Cancillería hasta que un fatídico 7 de noviembre le llega el cese.

A pesar de sus conocimientos activos del arte militar y de haber sido el creador de un ejército estable para la República, vista la poca confianza que se podía depositar en las fuerzas mercenarias, $y$, a pesar de que sus experiencias quedaron reflejadas en el Arte de la guerra, es conocida la anécdota que le sucedió en el campamento de Juan de Medici. Desde el principio de la batalla, el Secretario estaba en la brecha, aprovechando la ocasión para tomar nota de lo que oía y veía entre los pabellones del campamento. Allí estaban también Guicciardini y Aretino. Uno de los días la conversación recae sobre técnica militar y Maquiavelo discute con Juan, seguro de sus argumentos. El Medici lo desafia a que ponga en práctica sus teorías, haciendo formar a 3.000 soldados de a pie tal y como sugiere en el Arte de la guerra

12 Carta del 2 de enero de 1506

13 Roberto Ridolfi. Vira di Niccoló Machiavelli, Firenze, Sansoni, 1978? , p. 194. 
(De Re militari). Maquiavelo suda, grita, da órdenes y contraórdenes, profiere maldiciones, pero se revela incapaz de conseguir que formen ordenadamente. Los soldados sudan bajo el sol de mediodía y Maquiavelo está émpapado de sudor frío. Cansado ya de tanto jaleo Juan dice: «lo vo' cavar tutti noi di fastidio e che noi andiamo a desinare" ${ }^{14}$, y en un abrir y cerrar de ojos, con la ayuda del tambor, forma impecablemente a sus soldados haciendo que representen distintas figuras.

La actividad de Maquiavelo se extendió también a otros sectores. En 1520 , después de la quiebra del luqués Miguel Guinigi, que dejaba a sus acreedores florentinos un crédito impagado por valor de mil seiscientos florines, y aunque Nicolás no era ni abogado ni contable, fue enviado a Lucca para que reconociera el activo de la deuda ${ }^{15}$.

Como demuestran las muchas misiones realizadas ${ }^{16}$, los servicios a su patria fueron constantes y como servidor y como hombre se mantuvo siempre fiel al Estado, porque creia firmemente en el Estado como institución. Esa fidelidad le resultó en ocasiones muy dolorosa, como cuando en 1512 , viendo en peligro la estabilidad de su querida Florencia y siendo de convicciones profundamente republicanas, no vaciló en firmar el decreto que sancionaba la vuelta de los Medici a Florencia, en el que se reintegraba a los herederos de Lorenzo de Pedro de Medici el derecho a recuperar sus propiedades y a volver a ejercer cargos públicos ${ }^{17}$. A cambio de su fidelidad no recibió ninguna recompensa, los Medici lo apartaron de su cargo de la Cancillería, dejándolo cesante y en 1527 los republicanos que habian accedido al poder lo consideraron colaborador de los Medici ${ }^{18}$ haciendo caso omiso de los largos años de exilio sufridos.

Por los servicios prestados a la República, por las largas jornadas transcurridas a caballo en dirección a Alemania, Piombino, Francia o Forli, Maquiavelo no sólo no recibió compensaciones económicas, sino que, a menudo, tuvo que pedir dinero prestado para poder llegar al término de su misión. Asi sucedió en 1500 cuando en compañía de Francesco Della Casa fue enviado en misión ante el rey de Francia. A Della Casa le habian asignado una dieta diaria de 80 liras y al Secretario, por ser de menos categoría, una cantidad inferior y "sólo logró» que le asignaran una suma igual después de muchos trabajos y de quejarse de que tendría que gastar tanto como su

14 Ibid., p. 358.

15 Aprovechó su estancia para escribir el Sommario delle cose della città di Lucca y posteriormente también La vita di Castruccio da Lucca.

16. En la espléndida obra de Ridolfi, ya citada, se pueden encontrar las fechas v los detalles de todas sus misiones.

17 Documento autógrafo publicado por Alberto Maria Fortuna y Cristina Lunghetti: Scriptorium florentinum, M.A.P., Firenze, Corradino Mori, 1977, pp. 194-197.

8 Entre otras misiones que realizó para los Medici: en 1520 el cardenal Julio le habia encargado la redacción de la Historia de Florencia y un informe sobre los asuntos de Florencia para presentárselo a León $X$. Dos años más tarde le volvió a pedir su parecer a propósito de la reforma del Estado de Florencia. 
colega. Y aún así tuvo que desembolsar más de lo que recibión" ${ }^{14}$. Como se ve el problema de las dietas es un problema que de antiguo han tenido que capear los funcionarios. La situación llegó a hacerse desesperada en agosto de 1510. Maquiavelo se encuentra enfermo en Francia y, naturalmente sin recursos, por ello escribe a los Diez solicitando que le envien dinero: «se le non vogliono che io abbi a vendere e' cavalli e tornarmene a piè» ${ }^{20}$.

Aunque la República se hallaba cada vez más satisfecha del trabajo que realizaba su Secretario, y las certificaciones al respecto son numerosas, tampoco consiguió Maquiavelo el rango de embajador. Pudo influir en ello el hecho de que no fuera ni doctor, ni notario, como sabemos por el tratamiento que se le da en documentos públicos, donde su nombre nunca va precedido por el título de «ser» o de «messere». En las legaciones seguía siendo el segundón, el que redactaba los precisos y agudos informes y escrutaba las intenciones de reyes y señores, pero seguía firmando en segundo lugar o tenía que admitir, como en su misión a Alemania, que Vettori firmara las cartas que él redactaba para la Señoría.

En sus embajadas se mostraba mordaz, sutil y de lengua e ingenio finos, siguiendo una tradición netamente florentina, capaz de esgrimir la palabra como arma. En una ocasión Ludovico el Moro se quedó sin palabras cuando, al mostrarle a un embajador florentino una de las paredes de su palacio en la que había mandado representar el mapa de Italia con varios gallos, gallinas y pollos y a un moro, escoba en mano, que los barría a todos, le preguntó qué le parecía la alegoría. Contestó el florentino que la fantasía era bonita, pero que al tratar de barrer a los gallos fuera de Italia se estaba asfixiando con el polvo ${ }^{21}$. Tampoco halló respuesta el cardenal d'Amboise cuando, después de haberle dicho a Maquiavelo que los italianos no sabian nada sobre la guerra, tuvo que oir "che e' francesi non si intendevano dello stato; perché se se n'intendessono, non lascerebbono venire la Chiesa in tanta grandezza ${ }^{22}$.

Como legado de su país anotó cuidadosamente las costumbres de los habitantes de los paises que visitaba, relatando con acierto las informaciones más útiles para la Señoría, o dando consejos prácticos para viajeros poco avezados, no exentos de un cierto sentido del humor.

En su limitada visita a Alemania, en realidad al Tirol, percibió una serie de situaciones que dejó reflejadas en sus informes, por considerarlas de interés para las relaciones que la Señoría mantenía con sus gentes y con el emperador. Informa que los alemanes son ricos, «la ragione è questa: che vivono come poveri, non edificono, non vestono e non hanno masserizie in casa; e basta loro abundare di pane, di carne, e avere una stufa dove rifuggire il

\footnotetext{
19 Pasquale Villari, Maquiavelo, Barcelona, Ed. Grijalbo, 1975, p. 33.

20 Carta del 18 de agosto de 1510.

21 Villari, op. cit., p. 27.

22 Principe, III
} 
freddo: e chi non ha dell'altre cose, fa sanza e non le cerca»" ${ }^{23}$. Al no carecer de nada los alemanes no van a la guerra ni por necesidad, ni por afecto al emperador y si no se les paga abundantemente no se mueven. Por eso, aunque se encuentren en plena campaña: "se in capo a trenta di i danari non vengono, subito si partono, né li può reitenere prieghi o speranza o minaccia, mancandoli i danaris ${ }^{24}$.

Comprendió rápidamente que al emperador Maximiliano se le podía engañar sin dificultad, dado su carácter fácil y bondadoso, e hizo saber a la Señoria que, aunque sobre el papel el emperador parecia bien preparado para la guerra, en la práctica todo era distinto. Se decia que contaba con un poderoso ejército, pero en realidad como estaba formado por habitantes de distintas ciudades libres, éstas se comprometían a aportar un número determinado de hombres, mas el número total nunca llegaba a completarse. «E in esemplo ci è questo: che non molti anni sono li Svizzeri assaltarono lo stato di Massimiliano e la Svevia. Convenne sua maestà con queste comunità per reprimerli, e loro si obligorno tenere in campo quattordici mila persone: e vi se ne raccozzò la metà, perché quando quelli d'una comunità venivano, e li altri se ne andavano; in modo che lo imperadore, disperato di quella impresa, fece accordo colli Svizzeri e lasciò loro Basilea» ${ }^{25}$.

De los alemanes admiró sobre todo su enorme capacidad de previsión:

«E hanno in questo uno ordine bellissimo, perché hanno sempre in publico da mangiare e bere e ardere per uno anno: e cosi da lavorare le industrie loro, per potere in una obsidione pascere la plebe e quelli che vivono delle braccia, per uno anno intero sanza perdita" 26 .

De sus misiones en Francia, nos ha dejado un pormenorizado relato de cómo se organizaban los desplazamientos del rey y de la corte en los que todo estaba previsto y estipulado de antemano. Los precios de los alojamientos estaban sujetos a la cotización oficial: «cioè soldi uno per camera il di, dove ha a essere letto e cuccetta e mutati ad minus ogni otto di; danari due per uomo il giorno per e lingi cioè tovaglie e tovagliuoli, aceto e agresto; [...] danari due, ciascuno girono e per ciascuno cavallo, per lo stallaggio: e non sono tenuti per li cavalli darvi cosa alcuna, salvo che votarvi la stalla del letame ${ }^{27}$. El orden con el que planean las campañas del rey es tal que todos los detalles están previstos «in modo che allo arrivare ciascuno ha suo luogo, fino alla meretrice» ${ }^{28}$.

23 Ritratto delle cose della Magna, p. 69. Tanto para las citas sobre Alemania como para las que se refieren a la misión en Francia sigo la edición de Mario Martelli, Machiavelli. Tutte le opere, Firenze, Sansoni, 1971.

24 Rapporto delle cose della Magna. Fatto questo di 17 giugno 1508; p. 65.

25 Ritratto..., p. 70.

26 lbid., p. 68-69.

27 Ritratto di cose de Francia, p. 62.

28 Ibid., p. 61. 
Las Instrucciones para el que vaya de embajador a Francia casi podrían ser consideradas como un lejano antecedente de nuestras actuales guías de turismo, en las que se recogen una serie de consejos de carácter práctico, que resultan un tanto insólitos. Especifica la cuantía de las propinas que hay que dar a los porteros, atendiendo a su rango: " $A^{\prime}$ primi portieri, un ducato. $A$ ' secondi, due ducati. A' terzi che sono intimi, tre ducati. A' forieri, quattro ducati. A' trombettieri non date niente, ma ben li fare invitare a bere ${ }^{29}$.

Advierte más tarde que, si uno no quiere resultar engañado tiene que fijar de antemano el precio del alojamiento con los aposentadores reales. Así se libra uno luego de las discusiones. $Y$ añade: "Communiter in ciò che avete a fare di là, fate fare innanzi i patti chiari» ${ }^{30}$.

Curioso consejo es el de evitar el pan francés. En Italia el pan era entonces y es hoy todavía de corteza blanda, miga compacta y, generalmente, sin sal, diferente pues del crujiente pan francés, «Per la via come passate Asti, e massime per tutta la Savoia e Buriana, dove voi trovate buon pane, cioé che nos scrosci, fatene tôrre por la tavola vostra qualche poco; perché se ne truova assai bello, e per quel difetto non si può mangiare, ed è molto molesto ad uno lasso e delicato" ${ }^{31}$.

Pone en guardia al viajero para que no haga acopio de monedas que sólo tiene curso legal en territorio muy restringido, ya que luego no son aceptadas en otros lugares: «Guardatevi in Asti e nel Milanese di pigliar monete di Saluzzo» ${ }^{32}$.

Sin embargo el más entrañable de todos los consejos es el que se refiere al modo de preservar la ropa contra la obra demoledora de los ratones: "I vostri servitori abbino cura, per tutti li allogiamenti farete, alla roba; e guardino i panni e gli stivale da' topi, cioè appicchino i vostri stivali: che, benché questa sia cosa minima e ridicula, pure expertus loquon ${ }^{33}$. Después de tales indicaciones resulta prácticamente visible el sonrojo de un embajador, de vestimenta ya condicionada por las dietas, al comprobar los estragos cometidos por los ratones en su exiguo ajuar.

$$
\text { * * * }
$$

La indudable talla que Maquiavelo alcanzó como tratadista político ha desdibujado para la posteridad los rasgos de los que fue su verdadera personalidad como hombre. Prescindiendo de la circunstancia de que gran parte de los que lo condenan como practicante de una doctrina política ba-

29 Notula per uno che va ambasciatore in Francia, p. 55.

30 lbid., p. 55.

31 lbid., p. 55 .

32 Moneda perteneciente al pequeño marquesado de Saluzzo en el Piamonte.

33 Notula..., p. 55. 
sada en el oportunismo y el engaño han olvidado dos realidades fundamentales $^{34}$, tampoco se le puede combatir como si se tratara del iniciador e impulsor de una política cambiante que practicaban en aquel momento todos los Estados de Europa. El oportunismo político fue practicado por España y Francia, el emperador de Alemania, las milicias suizas, los grandes condotierós, por la Serenísima, el Estado de la Iglesia y el reino de Nápoles, y también por los distintos Estados del centro de Italia, pequeños tejedores de grandes intrigas.

Analizando, pues, su obra dentro de esas coordenadas históricas a Maquiavelo le cabe la responsabilidad de haber codificado con más inteligencia y rigor que otros escritores de su época una serie de prácticas políticas que fueron moneda de curso en Europa al iniciarse la Edad Moderna. Y, si humanamente hubiera sido tan maquiavélico "se hubiera situado" y no hubiera muerto pobre ${ }^{35}$ y en desgracia. Ello demuestra que quienes le aplican tal calificativo como sinónimo de hombre falaz y sin escrúpulos no hacen más que cometer una injusticia con él. Y resulta en parte paradójico que los que han magnificado su obra, precisamente porque la han denostado, hayan sido los que le han otorgado una fama de la que no gozaba entre sus contemporáneos. Las palabras de pueril aflicción con las que se lamenta porque Ariosto no lo ha citado en su poema son buena prueba de ello: "Io ho letto a questi di Orlando Furioso dello Ariosto, et veramente il poema è bello tucto, et in di molti luoghi mirabile. Se si trova costi, raccomandatemi ad lui, et ditegli che io mi dolgo solo che, havendo ricordato tanti poeti, che m'abbi lasciato indetro come un cazo, et ch'egli ha facto ad me quello in sul suo Orlando, che jo non farò a lui in sul mio $A$ sinos ${ }^{36}$.

En realidad estas palabras no son más que el desconsolado testimonio de un hombre que ha visto derrumbarse todas sus ilusiones, de un hombre que se siente amarga e injustamente postergado. Y los versos de Ariosto le proporcionan el pretexto para hacer públicos su desengaño y su desilusión por la falta de apoyo ante la dura condena que se le ha impuesto. Sus decepciones no serán vanas, porque en la desgracia del hombre de acción, del fiel servidor, germinará la naturaleza del clarividente político y la brillante personalidad del hombre de letras.

34 Según Macek no se tiene en cuenta: primero, que la producción más importante de Maquiavelo se publicó después de su muerte, por lo que no pudo protestar contras las interpretaciones erróneas, ni pudo evitar las correcciones, ni la censura; segundo, que los escritos del Secretario no pueden ser juzgados como si fueran la obra sistemática de un filósofo. J. Macek, Machiavelli e il machiavellismo, Firenze, La nuova Italia, 1980, pp. 6-7.

35 Murió pobre porque pobre habia vivido. Cuando después de su cese fue condenado a pagar una fianza de 1.000 florines de oro tuvo que acudir a tres amigos que salieron fiadores por él.

36 Carta de N. M. a Ludovico Alamanni, Florencia, 17 de diciembre de 1517. 